Physical

Therapy $(\mathrm{EJPT})$

https://ejpt.journals.ekb.eg

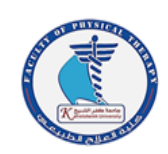

\title{
HIGH INTENSITY LASER THERAPY EFFECT ON PAIN IN PATIENTS WITH MYOFASCIAL TRIGGER POINTS
}

\author{
Hatem M. Ahmed ${ }^{1}$, Enas Abu Taleb ${ }^{2}$, Mohamed T. ELDESOKY², Yasser R. Lasheen², Fayrouz H. \\ Ameen ${ }^{*}$
}

1 Basic Science Department, Faculty of Physical Therapy, Badr University, Egypt
2 Basic Sciences Department, Faculty of Physical Therapy, Cairo University, Egypt

*Correspondence to

Mohamed T. Eldesoky,

Department of Basic

Science, Faculty of Physical

Therapy, Cairo University,

Cairo,

Tel:01001468054

Email;

enas_abutaleb@yahoo.co $\mathrm{m}$

Published online:

Sept 2020

\begin{abstract}
:
Purpose: to investigate the effect of high intensity laser therapy on pain intensity in patients with acute cervical myofascial trigger points in the upper trapezius muscle.

Methods: 50 patients (32 female and 18 male) suffering from myofascial trigger points in the upper trapezius muscle participated in this study.

They were all recruited from the out-clinic of the faculty of physical therapy Badr university. Their ages ranged from 20 to 40 years old with body mass index less than $25 \mathrm{~kg} / \mathrm{m}^{2}$. They were randomly allocated into two equal groups; group A $(\mathrm{n}=25)$ received traditional treatment only (transcutaneous electrical nerve stimulation, ultrasound, passive stretch and isometric exercise), group $B(n=25)$ received high intensity laser therapy with traditional treatment. duration of treatment was 2 sessions/week for 4 weeks. Measurement of the visual analogue scale was recorded before and after the intervention.

Results: Results showed that there was significant difference between the two groups in the outcome measures in the post treatment assessment, with the intervention administered by group (B) being more significant than the control group (A) at $(\mathrm{p}<0.001)$.

Conclusion: high intensity laser therapy was found to be significantly effective as a physical therapy modality for patients with cervical myofascial trigger points.

Key words: high intensity laser therapy, cervical myofascial trigger points, myofascial pain syndrome, visual analogue scale.
\end{abstract}

Myofascial pain syndrome (MPS) of the trapezius is considered one of the main causes of neck pain and characterized by deep, intense pain of the skeletal muscles and their fascia and by the presence of one or more myofascial trigger points (MTrPs), Although MTrPs can be formed in any muscle or muscle group, previous studies concluded that the upper trapezius muscle (UT) is the most commonly affected muscle $(3,4)$.

The motor innervation of the trapezius muscle is the accessory nerve. It helps to move the head (extension and rotation) and the shoulders (shrugging, lowering, 
posterior tipping, bringing the scapulae closer together) (5).

Also, The spinal accessory nerve innervates the sternocleidomastoid muscle (SCM) and runs underneath it or directly passes through the muscle belly, and thus, when MTrPs are created in the SCM from any microinjury it compresses and excites the nerve leading to pain that might be caused by ischemia in the UT muscle innervation (6). though, this complication has been taken into consideration in the treatment protocol by applying stretching techniques in the SCM muscle to decrease the load on the accessory nerve and make sure that the UT muscle has normal innervation.

Trigger points (TrPs) may result from trauma, overuse, mechanical overload, postural faults, or psychological stresses. Also the sedentary life style in all socities must be taken into account where too much time in static posturesleads to inhibition and laxity in the phasic muscles, while postural muscles will gradually become more tight which will cause imbalance between the dynamic and postural muscles leading to TrPs formation in the cervical region (7). This could lead to involuntary shortening, loss of oxygen supply, loss of nutrient supply, and increased metabolic demand on local tissues (8). MTrPs have been biopsied and found to contain contraction knots which are large, rounded, darkly stained muscle fibers with an increase in the average diameter of muscle fibers, thus the structure of contraction knots differs from that of normal muscle fibers. Functionally, excessive motor activity initiates several mechanisms that cause MTrPs to persist. Muscle contraction compresses local sensory nerves, reducing the axoplasmic transport of molecules that inhibit acetyl choline (Ach) release. Muscle contraction also compresses blood vessels, reducing the local supply of oxygen which-along with the metabolic demandsresults in a rapid depletion of local adenosine triphosphate (ATP)causing energy crisis that stimulates formation of TrP. In the energy crises theory, the pre-synaptic ATPs directly inhibit Ach release and the postsynaptic ATPs powers the calcium pump that return $\mathrm{ca}^{2+}$ into the sarcoplasmic reticulum. Hence, loss of ATP impairs the reuptake of $\mathrm{Ca}^{2+}$, which triggers actin and myosin leading to muscle spasm which in turn creats a vicious cycle(9).

Pain from MTrPs begins in peripheral tissues as nociception, transmitted by $\mathrm{A} \delta$ and $\mathrm{C}$-fiber afferent sensory neurons (nociceptors). Mechanical pressure, thermal stimuli, and many chemicals activate nociceptors; potassium ions, protons, and free $\mathrm{O} 2$ radicals are by-products of muscle metabolism and ATP energy crisis. Histamine is released from mast cells that migrate into injured tissues. Serotonin is released from platelets after they are exposed to platelet activating factor (released from the mast cells). Bradykinin is cleaved from serum proteins. All of these chemical "activators" bind to receptors in the nociceptor and initiate an action potential. Sensitizers are also released from damaged tissue including prostaglandins, leukotrienes, and substance P. Sensitizers decrease the activation threshold of a neuron, so that the nociceptor fires with less activation. This leads to peripheral sensitization and hyperalgesia (9).

Clinically, most MTrPs treatments either injection or physical therapy aiming to reach the MTrPs in the palpable taut band. Conventional treatments usually include electro therapy, manual therapy, cold and heat therapy, local anesthetics, and needle injection, stretching and exercises are frequently used (10).

The impact of ultrasound (US) on trigger point sensitivity has previously been investigated. It significantly reduced pain pressure sensitivity of MTrPs with an average $44.1 \%$ increase in the pain pressure threshold readings from a trigger point within the trapezius muscle after a 5-min exposure to ultrasound(11).

Desai et al, mentioned that Multiple randomized controlled trials (RCTs) studies of ultrasound on MPS have been conducted from 1995 to 2012, and found a significant improvement in pain, range of motion and number of trigger points and concluded that it is an effective tool in the management of MTrPs (12).

While using ultrasound, the gate control mechanism could be mentioned due to excitation of A-beta mechanoreceptors. In this condition, impulses produced from mechanoreceptors enter the spinal cord and quick pain impulses become inhibited and pain would be blocked, as well as tissue repair created by the mechanical effects of US might be the reason behind some of the positive effects on MTrPs that's why, this study showed that US was effective for treatment of MTrPs (13).

Johnson et al described the Transcutaneous electrical nerve stimulation (TENS) as a well-known modality for the management of acute and chronic pain using various wave forms, amplitudes and frequencies on peripheral nerves. Desai et al in 2013 also proved by many RCTs from 1989 to 2009 that it is an effective modality in the management of MTrP (14).

According to the gate control theory of pain, highfrequency and low-intensity TENS activates largediameter $A \beta$ fibers, which at dorsal horn level inhibits the incoming nociceptive volley transmitted via smalldiameter, slow-conducting $\mathrm{A} \delta$ and $\mathrm{C}$ fibers innervating spatially-adjacent skin areas(15).

Furthermore, Stretching was used in the treatment of MTrPs. stretching is a sustained external, elongation 
force, applied with overpressure at the end of the range by manual contact or a mechanical device to elongate a shortened muscle-tendon unit and periarticular connective tissues by moving a hypo-mobile joint just beyond the available range of motion (ROM) that was limited by adhesions, contractures or scars of the soft tissues (16).

laser therapy is used to treat musculoskeletal pathologies, which involves the application of red and near-infrared light over injured tissues or superficial wounds to increase soft tissue healing and for its ability to manage acute and chronic pain (17).

HILT, is considered one of the means of phototherapeutic devices that gained popularity for treating acute and chronic inflammatory pain and related impairments(18).But lately, it has been proved that HILT has deeper effect on inflammation and edema, analgesic effects and stimulation of joints more deeply. Thus, the application of HILT for MPS may improve pain and function(19).

There is a lack in the available literature as few studies had been conducted to investigate the effect of HILT on musculoskeletal disorders and proved its significant effect, so further more investigations and researches are needed on different musculoskeletal conditions such as myofascial trigger points. So, the purpose of this study is to investigate the effect of HILT on musculoskeletal disorders (MSD) and prove its significant effect.

\section{Patients and Methods}

\subsection{Study participants and recruitment criteria:}

Fifty patients (32 female and 18 male) suffering from MTrP in the upper trapezius muscle were recruited in the study from the out-patient clinic of faculty of physical therapy BADR university. Their ages ranged from 20 to 40 years old with body mass index less than $25 \mathrm{~kg} / \mathrm{m}^{2}$. They were randomly assigned into two equal groups using the numbering model of randomization where odd numbers were the control group while the even numbers were the intervention group.

According to The Delphi study, which included international experts in the MPS, who approved the diagnostic criteria for MTrPs to be a taut band, a hypersensitive spot, and referred pain. Based on the responses during all Delphi rounds, it seems that at least two of the three criteria should be present for diagnosis of a MTrP (20).

Subjects that exhibited any of the following were excluded from the study:

Diagnosis of fibromyalgia syndrome, history of a whiplash injury, history of cervical spine surgery, diagnosis of cervical radiculopathy or myelopathy determined by their primary care physician, having undergone myofascial pain therapy within the past 3 months before the study, patients who had local anesthetics, and/or steroid injections into the trigger points within 6 months, patients with cervical disc herniation, cervical spinal stenosis, or any pathological findings on cervical X-rays.

\subsection{Control Group:}

The first study group (A) composed of 25 patients (16 female and 9 male) who received traditional treatment only in the form of TENS, US, passive stretching and isometric exercises for 4 weeks.

\subsection{Intervention group:}

The second study group (B), composed of 25 patients (16 female and 9 male) who received HILT with traditional treatment for 4 weeks.

2.4.Instrumentation:

\subsubsection{Therapeutic equipments:}

2.4.1.1. The treatment protocol was achieved by using TENS device Chattanooga, model 2760, serial number T11238, $120-240 \mathrm{~V}, 50 / 60 \mathrm{~Hz}$, made in Mexico, manufactured 2/2016, the frequency of the current was $100 \mathrm{~Hz}$ and the duty cycle was 250 micro second(15).

2.4.1.2. Ultrasound device Chattanooga, model 2760, serial number T11238, $120-240 \mathrm{~V}, 50 / 60 \mathrm{~Hz}$, made in Mexico, manufactured 2/2016 was used. With the following parameters: frequency $1 \mathrm{MHz}$ with intensity $0.5 \mathrm{~W} / \mathrm{cm}^{2}$, pulsed mode for 5 minutes (21).

2.4.1.3. HILT device ZIMMER OPTON PRO, serial number $1520003306,100-240 \mathrm{~V}, 50 / 60 \mathrm{~Hz}$, max. 0.95A, made in Germany, manufactured 4/2015 was used with a dual wavelengths $(810 \mathrm{~nm}$ and $980 \mathrm{~nm})$, $\max 7 \mathrm{~W} \mathrm{CW}$.

The therapeutic dose of laser therapy is determined by the power density at the target tissue, color (amount of melanin) and type of the tissues. In people with darker skin, due to the large count of the melanin in the epidermal layer which absorbs wide range of wavelengths in the light beam, the laser is absorbed in the epidermal layer before it reaches to the targeted deeper tissue. However, due to the longer wavelength of the HILT, laser light can pass the melanin layer in the epidermis and transfer the therapeutic dose deeply without any absorption. The purpose of the researches in the past decade was to increase power density and dose. That is why the therapeutic outcomes has been improved. The World Association of Laser Therapy concluded that target tissues need a dose of 5-7 J/cm2 to stimulate a biological cellular response (22).

\subsubsection{Measurement equipment:}

\subsubsection{Visual Analogue Scale (VAS):}

Pain level was assessed by visual analogue scale. VAS is a ten $\mathrm{cm}$ line anchored at each end with words such as no pain and the worst pain possible. VAS record was taken before starting treatment (first 
record) and at the end of the total period of treatment after 4 weeks (second record) (23).

2.5.Procedures of the study:

The experimental protocol was explained in details for every patient before starting the initial assessment, and a written consent form was signed by each patient before starting. The treated patients were instructed to report any side effects during the treatment sessions.

\subsubsection{Therapeutic Procedures:}

TENS treatment protocol:

The negative electrode of the TENS unit was placed on the MTrP of the upper trapezius muscle, and the positive electrode was placed near the insertional site of the muscle. The intensity was set to stimulate the sensory nerves where the patients feel the current passing through the electrodes but it is not strong enough to stimulate the muscle to contract. The current was applied for 20 minutes (10).

\subsubsection{US treatment protocol:}

The ultrasound with transducer head of $5 \mathrm{~cm}^{2}$ was applied over the area of MTrPs of upper trapezius muscle. The treatment was carried out with pulsed mode, frequency $1 \mathrm{MHz}$, intensity $0.5 \mathrm{~W} / \mathrm{cm} 2$ and applied by overlapping circular technique at a rate of $4 \mathrm{~cm} / \mathrm{s}$ for 5 minutes (21).

\subsubsection{HILT treatment protocol:}

The laser probe - with the small spacer $\left(3.1 \mathrm{~cm}^{2}\right)$ - was applied perpendicularly on the skin and with slight contact, directed on the MTrP of the upper trapezius muscle according to its location by the assessment techniques. Using parameters of 3 watts, $5 \mathrm{~Hz}, 50 \%$ duty cycle, 20 joule/ point for 13 seconds with 6.4 $\mathrm{j} / \mathrm{cm}^{2}(22)$.

2.5.4. Passive stretching and exercise treatment protocol:

Stretching of the upper trapezius muscle and SCM bilaterally with passive low intensity stretching technique that was applied for 30 seconds and 4 repititions with 1 minute rest between the repititions and instructions for the patients to relax while stretching to gain the optimum relaxation effect (16).

All the patients performed an isometric exercise program for the upper trapezius muscle for 3 sets of 10 repetition for both sides while the patients being in sitting position and the therapist standing behind them giving certain amount of resistance to perform isometric contraction with rest periods of 30 seconds between the sets (24).

All the patients were positioned in sitting position with both arms rested on their labs in all the treatment protocol.

\subsubsection{Measurement tools:}

2.6.3.1. Visual analogue scale (VAS): was done before and after the treatment program (23)
The IBM SPSS statistics 22 software was used for statistical analysis. The analysis of data for this study was done using descriptive statistics and a $2 \times 2$ mixed model Analysis of Variance (ANOVA) with two groups (control vs. intervention) as the between subjects factor and two times for measuring the dependent variables (pre-treatment and post- treatment) as the within subjects factor. The P-value was set at 0.05. The differences in demographic characteristics for both groups were assessed using unpaired t-tests. For further comparison between both groups, unpaired t-test was conducted to compare between pre treatment and post treatment between both groups for all dependent variables. Furthermore, To show the difference between pre and post treatment values in each group, paired ttest was conducted for each group. A sample size of 25 participants in each group was determined by conducting a preliminary power analysis with a power $80 \%$.

\section{Results}

In this study, 50 patients with acute cervical myofascial trigger points of upper trapezius muscle were assigned randomly into two groups.

Group (A):

Twenty five patients were included in this group. The data of the participants was represented in table (1). the subjects mean age was $(30.12 \pm 5.66)$ years, mean weight was(67.7 \pm 8.59$) \quad$ kilograms $(\mathrm{Kg})$, mean height was $(170.26 \pm 7.95)$ centimeters $(\mathrm{cm})$, and mean BMI was $(23.26 \pm 1.54)\left(\mathrm{Kg} / \mathrm{m}^{2}\right)$.

Group (B):

Twenty five patients were included in this group. The data of the participants was represented in table (1). the subjects mean age was(29.22 \pm 5.3$)$ years, mean weight was (64.98 \pm 9.9$)$ kilograms $(\mathrm{Kg})$, mean height was (167.44 \pm 9.32$)$ centimeters $(\mathrm{cm})$, and mean BMI was $(23.04 \pm 1.55)\left(\mathrm{Kg} / \mathrm{m}^{2}\right)$.

There was no significant difference between both groups in their ages, weights, heights, and BMI as their P-values were (0.56), (0.3), (1.15), and (0.62) respectively.

Table (1): Physical characteristics of patients in both groups (A\&B).

\begin{tabular}{llllll}
\hline Items & Group A & Group B & Comparison & \\
& & & & $\begin{array}{l}\text { Signific } \\
\text { ance }\end{array}$ \\
& Mean \pm SD & Mean \pm SD & t-value & P-value & \\
\cline { 2 - 6 } Age (yrs) & $\begin{array}{l}30.12 \pm 5.6 \\
6\end{array}$ & $29.22 \pm 5.3$ & 0.58 & 0.56 & NS
\end{tabular}




\begin{tabular}{|c|c|c|c|c|c|}
\hline $\begin{array}{l}\text { Weight } \\
(\mathrm{Kg})\end{array}$ & $67.7 \pm 8.59$ & $64.98 \pm 9.9$ & 1.03 & 0.3 & NS \\
\hline $\begin{array}{l}\text { Height } \\
(\mathrm{cm})\end{array}$ & $\begin{array}{l}170.26 \pm 7 \text {. } \\
95\end{array}$ & $\begin{array}{l}167.44 \pm 9 . \\
32\end{array}$ & 1.15 & 0.25 & NS \\
\hline $\begin{array}{l}\mathrm{BMI} \\
\left(\mathrm{Kg} / \mathrm{m}^{2}\right)\end{array}$ & $\begin{array}{l}23.26 \pm 1.5 \\
4\end{array}$ & $\begin{array}{l}23.04 \pm 1.5 \\
5\end{array}$ & 0.49 & 0.62 & NS \\
\hline
\end{tabular}

NS=non significance

\section{The pain level:}

The pretreatment Pain Level (VAS) mean value of group (A) was $(6.6 \pm 1.25)$ and for post treatment was $(4.76 \pm 1.16)$, while The pretreatment Pain Level (VAS) mean value of group (B) was $(6.68 \pm 1.24)$ and for post treatment was (2.6 \pm 0.7$)$ shown in Table (2) and figure (1).

The $2 \times 2$ mixed-model ANOVA analysis demonstrated significant improvements in the pain level for both groups after treatment as the main effect of time was statistically significant $(\mathrm{p}<0.0001)$, but experimental group showed significant improvement than the control group post treatment as the main effect of group was statistically significant $(p<0.001)$ and time $\times$ group interaction effect was also significant $(\mathrm{p}<0.0001)$ as shown in Table (2).

Table(2): Descriptive statistics of the pain level and $2 \mathrm{X}$ 2 mixed-model ANOVA of pain level between both groups pre-treatment and post-treatment.

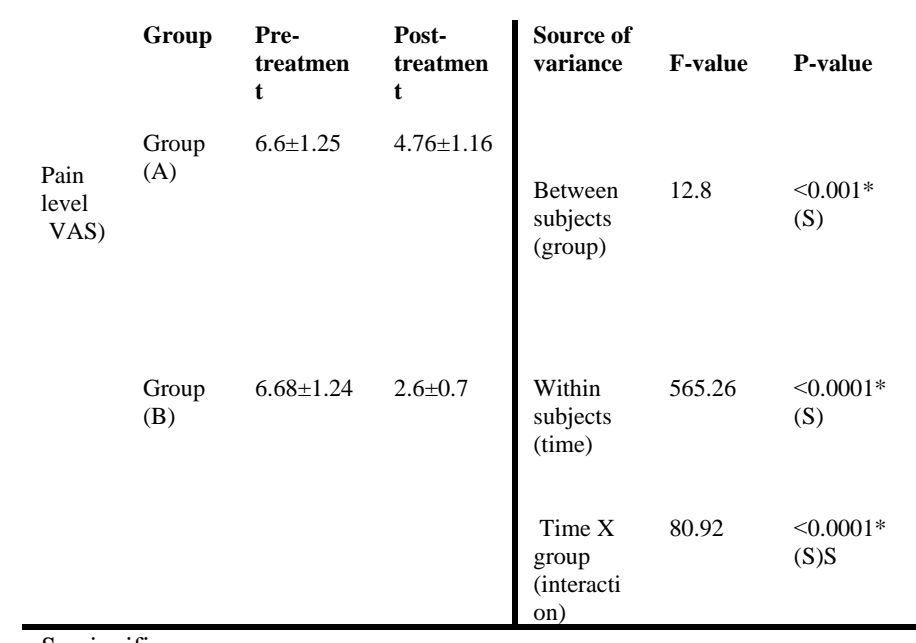

$\mathrm{S}=$ significance

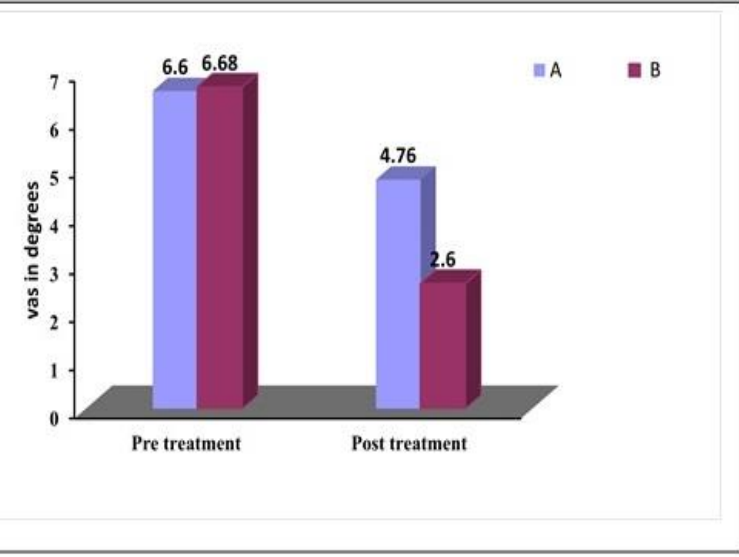

Fig (1) : Mean values of VAS in degrees before and after treatment in both groups.

For further comparison between pre-treatment and post treatment pain level between both groups unpaired t-test was conducted. There was no significant difference between both groups in pretreatment values where p-value was (0.82), while there was a significant difference in the post treatment values where $p$-value was $(0.0001)$ as revealed by the unpaired t-test as shown in table (3).

Table(3): Unpaired t-test for pre and post treatment values between both groups for pain level

\begin{tabular}{lllll} 
Variable & Pre treatment & \multicolumn{2}{c}{ Post treatment } \\
& t-value & p-value & t-value & p-value \\
Pain level & 0.22 & 0.82 & 7.92 & 0.0001 \\
(VAS) & & & & $(\mathrm{s})$ \\
\hline $\mathrm{S}=$ significance & & & &
\end{tabular}

To show the difference between pre and post treatment values in each group, paired t-test was conducted for each group. For group (A), there was a significant difference in the paired t-test between pre and post treatment pain level as P-value was (0.0001). For group (B), there was a significant difference in the paired t-test between pre and post treatment pain level as P-value was (0.0001) as shown in table (4).

Table(4): paired t-test between pre and post treatment values in each group

\begin{tabular}{lllll}
$\begin{array}{l}\text { Comparison } \\
\text { between pre and } \\
\text { post treatment } \\
\text { values in each } \\
\text { group }\end{array}$ & t-value & p-value & t-value & p-value \\
$\begin{array}{l}\text { Pain level } \\
\text { (VAS) }\end{array}$ & 12.33 & 0.0001 & 20.46 & 0.0001 \\
\hline
\end{tabular}

\section{Discussion}

In the present study, we investigated the analgesic effect of the HILT on cervical MTrPs in the upper trapezius muscle and Our results revealed that the intervention and control groups had significant 
improvement in post treatment evaluation procedure although the improvement was more significant in the intervention group. This variation in the improvement between the groups was due to the effect of HILT in decreasing pain and inflammation at the site of the trigger point.

the decrease in pain achieved by HILT might be due to multiple mechanisms in the central nervous system (CNS), the peripheral nervous system (PNS) and at the level of the injured tissues. At the level of the CNS, there was significant increase in the secretion of endogenous opioids, b-endorphins and dynorphins which are stimulated by laser therapy that consequently inhibit pain sensations. As for the peripheral nervous system, laser therapy has been reported to decrease the secretion of substance $P$ (responsible for sensitizing pain transmitting neurons and leading to hyper-algesia), also laser therapy might increase the latency and decrease the conduction velocity of sensory nerves by inhibiting A-delta and C-fiber transmission; which in turn may decrease the transmission of pain signals. At the tissue level, laser therapy may also reduce the release of histamine and bradykinin in injured tissues and increase the pain threshold. These multiple actions of laser therapy explain the underlying mechanisms involved in the control of pain in MPS(19).

Our results were supported by astudy done by ŠtiglićRogoznica et al who stated that the patients treated with HILT showed a great and statisticaly significant reduction in pain. Therefore, HILT demonstrates to have a very good and quick analgesic effect(25).

In their study, Kheshie et al also agree with our results as they reported that HILT has significant effect in decreasing pain and inflammation (26).

High-intensity combined LASER wavelengths of 830 $\mathrm{nm}$ and $1064 \mathrm{~nm}$, which produce a better transparency with less scattering and a high energy transfer, was found to be better than TENS in improving both pain and paraesthesia as well as neurophysiological parameters in CTS (27).

Therefore, HILT has a great significant effect on lumbar disc protrusion, as it can speed up improvement of the lumbar segment motion, angle of straight leg raising, pain and over all function (28).

A study comparing between HILT and traction effect on cervical spondylosis demonstrated analgesic efficacy, and improved global mobility. The traction method was similarly effective as HILT only in the first period, i.e., immediately after the procedures and in medium-term follow-up. HILT showed a better therapeutic effect in long-term follow-up, which again supports our outcomes (29).

HILT also had significant effect on relieving pain in patients with frozen shoulder after 3 weeks treatment and after a short term follow up of 8 weeks. However, no difference was observed at the final follow-up (12 weeks) (30).

Angelova and Ilieva, investigated the effect of highintensity laser on pain in patients with knee osteoarthritis. Pain intensity was recorded by VAS and dolorimeter, which showed a significant pain decrease in patients after seven days, They also stated that The effectiveness of HILT is based on the specific and characteristic high peak power of the laser pulse which conveys a large amount of energy in a short time compared to the long time needed to deliver the same amount of energy by low level laser treatment LLLT (making risk of heating and tissue damage) (31).

In his study, Gocevska has shown that patients with chronic low back pain treated with HILT has significantly reduced pain intensity and its positive effect maintained for three months (32).

Most of the literature considering HILT and the studies conducted on its effect, found it to be significantly effective in alleviating pain. Although all these studies were conducted on different musculoskeletal disorders as knee osteoarthritis, lumbar and cervical disorders, different injuries in peripheral joints and post-operative pain and inflammation, but none or few studies were conducted to examine the effect of HILT on MTrPs and MPS. In this study the effect of HILT on MTrPs was investigated and found to have a significant effect in decreasing pain.

\section{Conclusion}

Application of HILT together with the traditional treatment had a valuable effects on the myofascial trigger points as evidenced by the highly significant decreases in VAS. In comparison with the traditional treatment alone.

\section{Acknowledgments}

This work was supported by BADR university by providing all the equipments and devices used in the study with no financial ties.

\section{Conflict of Interests}

The authors declare no conflict of interest.

\section{References}

1. Genebra CV, Maciel NM, Bento TP, Simeão SF, De Vitta A. Prevalence and factors associated with neck pain: a population-based study. Brazilian 
journal of physical therapy. 2017 Jul 1;21(4):27480.

2. Yue P, Liu F, Li L. Neck/shoulder pain and low back pain among school teachers in China, prevalence and risk factors. BMC public health. 2012 Dec;12(1):1-8.

3. Dundar U, Turkmen U, Toktas H, Solak O, Ulasli AM. Effect of high-intensity laser therapy in the management of myofascial pain syndrome of the trapezius: a double-blind, placebo-controlled study. Lasers in medical science. 2015 Jan 1;30(1):32532.

4. Amini A, Goljaryan S, Shakouri SK, Mohammadimajd E. The Effects of Manual Passive Muscle Shortening and Positional Release Therapy on Latent Myofascial Trigger Points of the Upper Trapezius: A Double-Blind Randomized Clinical Trial. Iranian Red Crescent Medical Journal. 2017 Sep;19(9).

5. Nyemb PM, Fontaine C, Jean-Marc N. Review of the Literature on Anatomical Variations of the Trapezius Muscle. MOJ Anat \& Physiol. 2017;4(5):00152.

6. Kim SJ, Lee JH. Effects of sternocleidomastoid muscle and suboccipital muscle soft tissue release on muscle hardness and pressure pain of the sternocleidomastoid muscle and upper trapezius muscle in smartphone users with latent trigger points. Medicine. 2018 Sep;97(36).

7. Ziaeifar M, Arab AM, Karimi N, Nourbakhsh MR. The effect of dry needling on pain, pressure pain threshold and disability in patients with a myofascial trigger point in the upper trapezius muscle. Journal of bodywork and movement therapies. 2014 Apr 1;18(2):298-305.

8. Ruiz-Sáez M, Fernández-de-las-Peñas C, Blanco CR, Martínez-Segura R, García-León R. Changes in pressure pain sensitivity in latent myofascial trigger points in the upper trapezius muscle after a cervical spine manipulation in pain-free subjects. Journal of manipulative and physiological therapeutics. 2007 Oct 1;30(8):578-83.

9. McPartland JM, Simons DG. Myofascial trigger points: translating molecular theory into manual therapy. Journal of Manual \& Manipulative Therapy. 2006 Oct 1;14(4):232-9.

10. Hou CR, Tsai LC, Cheng KF, Chung KC, Hong CZ. Immediate effects of various physical therapeutic modalities on cervical myofascial pain and trigger-point sensitivity. Archives of physical medicine and rehabilitation. 2002 Oct 1;83(10):1406-14.

11. Srbely JZ, Dickey JP. Randomized controlled study of the antinociceptive effect of ultrasound on trigger point sensitivity: novel applications in myofascial therapy?. Clinical rehabilitation. 2007 May;21(5):411-7.

12. Desai MJ, Saini V, Saini S. Myofascial pain syndrome: a treatment review. Pain and therapy. 2013 Jun 1;2(1):21-36.

13. Sarrafzadeh J, Ahmadi A, Yassin M. The effects of pressure release, phonophoresis of hydrocortisone, and ultrasound on upper trapezius latent myofascial trigger point. Archives of physical medicine and rehabilitation. 2012 Jan 1;93(1):72-7.

14. Johnson M, Martinson M. Efficacy of electrical nerve stimulation for chronic musculoskeletal pain: a meta-analysis of randomized controlled trials. Pain. 2007 Jul 1;130(1-2):157-65

15. Peng WW, Tang ZY, Zhang FR, Li H, Kong YZ, Iannetti GD, Hu L. Neurobiological mechanisms of TENS-induced analgesia. NeuroImage. 2019 Jul 15;195:396-408.

16. Kisner C, Colby LA, Borstad J. Therapeutic exercise: foundations and techniques. Fa Davis; 2017 Oct 18.

17. Starkey C. Therapeutic modalities. FA Davis; 2013 Jan 23.

18. Parr JJ, Larkin KA, Borsa PA. Effects of class IV laser therapy on exercise-induced muscle injury. Athletic Training and Sports Health Care. 2010 Nov 1;2(6):267-76.

19. Song HJ, Seo HJ, Lee Y, Kim SK. Effectiveness of high-intensity laser therapy in the treatment of musculoskeletal disorders: A systematic review and meta-analysis of randomized controlled trials. Medicine. 2018 Dec;97(51).

20. Fernández-de-las-Peñas C, Dommerholt J. International consensus on diagnostic criteria and clinical considerations of myofascial trigger points: a Delphi study. Pain Medicine. 2018 Jan 1;19(1):142-50.

21. Srbely JZ, Dickey JP, Lowerison M, Edwards AM, Nolet PS, Wong LL. Stimulation of myofascial trigger points with ultrasound induces segmental antinociceptive effects: a randomized controlled study. Pain. 2008 Oct 15;139(2):260-6.

22. Karlekar A, Bharati S, Saxena R, Mehta K. Assessment of feasibility and efficacy of Class IV laser therapy for postoperative pain relief in offpump coronary artery bypass surgery patients: A pilot study. Annals of cardiac anaesthesia. 2015 Jul;18(3):317.

23. Boonstra AM, Preuper HR, Reneman MF, Posthumus JB, Stewart RE. Reliability and validity of the visual analogue scale for disability in patients with chronic musculoskeletal pain. International journal of rehabilitation research. 2008 Jun 1;31(2):165-9. 
24. Acar B, Yilmaz ÖT. Effects of different physiotherapy applications on pain and mobility of connective tissue in patients with myofascial pain syndrome. Journal of Back and Musculoskeletal rehabilitation. 2012 Jan 1;25(4):261-7.

25. Štiglić-Rogoznica N, Stamenković D, FrlanVrgoč L, Avancini-Dobrović V, Schnurrer-Luke Vrbanić T. Analgesic effect of high intensity laser therapy in knee osteoarthritis. Collegium antropologicum. 2011 Sep 25;35(2):183-5.

26. Kheshie AR, Alayat MS, Ali MM. High-intensity versus low-level laser therapy in the treatment of patients with knee osteoarthritis: a randomized controlled trial. Lasers in medical science. $2014 \mathrm{Jul}$ 1;29(4):1371-6.

27. Casale R, Damiani C, Maestri RA, Wells CD. Pain and electrophysiological parameters are improved by combined 830-1064 high-intensity LASER in symptomatic carpal tunnel syndrome versus Transcutaneous Electrical Nerve Stimulation. A randomized controlled study. European journal of physical and rehabilitation medicine. 2012 Jul 20;49(2):205-11.

28. Chen L, Liu D, Zou L, Huang J, Chen J, Zou Y, Lai J, Chen J, Li H, Liu G. Efficacy of high intensity laser therapy in treatment of patients with lumbar disc protrusion: A randomized controlled trial. Journal of back and musculoskeletal rehabilitation. 2018 Jan 1;31(1):191-6.

29. Haładaj R, Pingot M, Topol M. The effectiveness of cervical spondylosis therapy with Saunders traction device and high-intensity laser therapy: a randomized controlled trial. Medical science monitor: international medical journal of experimental and clinical research. 2017;23:335.

30. Kim SH, Kim YH, Lee HR, Choi YE. Short-term effects of high-intensity laser therapy on frozen shoulder: a prospective randomized control study. Manual therapy. 2015 Dec 1;20(6):751-7.

31. Angelova A, Ilieva EM. Effectiveness of high intensity laser therapy for reduction of pain in knee osteoarthritis. Pain Research and Management. 2016 Oct;2016.

32. Gocevska M, Nikolikj-Dimitrova E, GjerakaroskaSavevska C. Effects of high-intensity laser in treatment of patients with chronic Low Back pain. Open access Macedonian journal of medical sciences. 2019 Mar 30;7(6):949. 